\title{
OPTIMALISASI KECEPATAN INTERNET MENGGUNAKAN PROXY SQUID DI PT. UTAC MANUFACTURING SERVICES INDONESIA
}

\author{
Syafrianto \\ Program Studi Manajemen Informatika, \\ STMIK Nusa Mandiri Jakarta \\ E-mail: syafrianto.yfr@nusamandiri.ac.id
}

\begin{abstract}
ABSTRAKS
Kemajuan dunia informasi teknologi dan perkembangan jumlah pengguna internet karenakan adanya perkembangan teknologi yang semakin meningkat. Pengguna layanan internet saat ini telah dimanfaatkan oleh siapa saja dan bidang mana saja. Salah satunya bidang manufacturing atau di pabrik, pemanfaatan teknologi internet telah dirasakan langsung oleh pihak perusahaan atau pabrik yang dapat meningkatkan proses dan hasil kerja menjadi lebih optimal. Terbatasnya kecepatan internet dan banyaknya pengguna dapat mempengaruhi kecepatan akses dan tidak dibarengi dengan penambahan suatu teknologi yang dapat mengatasi masalah internet dengan biaya yang dapat minimal. Berdasarkan kendala akses internet, penelitian ini mengusulkan perlunya instalasi proxy server dengan menggunakan squid pada sistem operasi Centos. Tujuan dari penelitian ini adalah untuk merancang dan mengimplementasikan proxy server dengan menggunakan squid sehingga dapat mempercepat akses internet. Dengan akses internet yang lebih cepat maka dapat meningkatkan kinerja perusahaan PT. UTAC Manufcaturing Sevrices Indonesia.
\end{abstract}

Kata Kunci: proxy server, squid, squid stable, squid common, squid lang-pack.

\begin{abstract}
S
The progress of the world of information technology and the development of the number of internet users due to the development of technology is increasing. Today's internet service users have been used by anyone and in any field. One of them is manufacturing or in the factory, the use of internet technology has been felt directly by the company or factory that can improve the processes and work results to be more optimal. The limited speed of the internet and the number of users can affect the speed of access and are not accompanied by the addition of a technology that can overcome the problem of the internet at a minimal cost. Based on internet access constraints, this study proposes the need to install a proxy server using Squid on the Centos operating system. The purpose of this research is to design and implement a proxy server using Squid so that it can speed up internet access. With faster internet access, it can improve the performance of the company PT. UTAC Manufcaturing Sevrices Indonesia.
\end{abstract}

Keywords: proxy server, squid, squid stable, common squid, squid lang-pack.

\section{PENDAHULUAN}

PT. UTAC Manufacturing Services Indonesia merupakan sebuah industri yang bergerak di bidang Assembly dan testing semikonduktor yang berlokasi di KIIC Karawang, Saat ini sudah menggunan Teknologi Informasi sebagai pendukung untuk kemajuan industri. Perkembangan dan kemajuan teknologi saat ini diimbangi dengan meningkatnya jumlah pengguna internet yang pesat, hal ini dikarenakan semakin banyaknya masyarakat yang menyebarkan informasi melalui internet. Saat ini sebagian masyarakat menjadikan internet sebagai kebutuhan utama dan cenderung meningkat dari hari ke hari. Meningkatnya kebutuhan teknologi internet tersebut dibuktikan juga dengan penggunaan internet yang telah merambah ke berbagai bidang, termasuk bidang industry Manufacture.
Meningkatnya jumlah pengguna internet di beberapa instansi yang tidak diimbangi dengan penambahan bandwidth dikarenakan tingginya faktor biaya, sehingga memunculkan beberapa permasalahan. Permasalah tersebut terkait dengan kecepatan akses internet yang dirasa lama oleh para pengguna. Langkah mudah yang dapat dilakukan untuk menghemat bandwidth adalah menggunakan squid proxy. Squid banyak digunakan oleh perusahaan untuk mengatur lalu lintas web, meningkatkan kinerja, akses internet yang lebih cepat. Sehingga permasalahan akses internet agar lebih cepat dapat ditangani dengan adanya instalasi squid proxy server tanpa perlu membeli bandwidth dan mengeluarkan anggaran biaya yang besar. Tujuan dari penelitian ini adalah untuk merancang dan mengimplementasikan proxy server dengan menggunakan squid sehingga dapat mempercepat akses internet. Dengan akses internet yang lebih cepat maka dapat 
meningkatkan kinerja baik produksi maupun non produksi.

Proxy Server adalah server yang berguna sebagai perantara antara klien dengan server gateway sebelum berhubungan ke internet. Cache proxy adalah sebuah cache server yang berguna untuk menyimpan atau menampung informasi ( $h t t p)$ yang pernah diakses oleh sebuah komputer maupun computer lain yang masih berada didalam satu jaringan local yang sama dengan proxy server tersebut. Proxy server ini berjalan pada sistem operasi Centos dan software yang dapat digunakan di Centos adalah squid.

Fungsi proxy dapat dilakukan oleh berbagai software tergantung kepada jenis proxy yang dibutuhkan, misalnya web proxy, rlogin proxy, ftp proxy dan seterusnya. Di sisi klient sering kali dibutuhkan software tertentu agar dapat menggunakan proxy server ini, seperti misalnya dengan menggunakan SOCKS.

Proxy server adalah mesin yang mempunyai sistem daemon (telnetd, fipd, etc) normal diganti dengan server khusus. Server ini disebut dengan proxy server dimana secara biasa hanya mengijinkan untuk membuat koneksi kedepan. Proxy server biasanya mempunyai keamanan lebih dari server biasa, dan seiring mempunyai variasi mekanisme keabsahan yang luas termasuk adalah "one-shot" sistem Password.

Proxy server yang cukup populer saat ini adalah squid, karena selain gratis juga mendukung Internet Cache Protocol (ICP). ICP digunakan untuk pertukaran data tentang suatu Uniform Resource Locator (URL) dengan cache-cache lainnya. Secara sederhana, squid dapat dikatakan sebagai software yang diaplikasikan untuk membuat http atau ftp cache. Cara kerja squid dapat dianalogikan seperti web browser yang menyimpan data suatu site di harddisk sehingga untuk menampilkan site yang sama tinggal mengambil data di cache-nya. Selain itu, squid dapat melakukan filtering, yaitu squid dapat mem-block permintaan client terhadap URL URL tertentu, sehingga pengelola jaringan dapat lebih santai tanpa khawatir adanya penyalahgunaan yang tidak dikehendaki.

\section{METODE}

Alur penelitian yang dilakukan dalam penelitian terdiri dari beberapa proses tahapan, hal ini bertujuan agar memberikan hasil yang baik dan sesuai dengan tujuan dari penelitian. Alur penelitian digambarkan dalam sebuah flowchart atau diagram alir yang memiliki tujuan untuk mempermudah penyelesaian suatu masalah khususnya masalah yang perlu dipelajari dan dievaluasi lebih lanjut. Flowchart pada penelitian ini dipaparkan berikut ini : 1) Pengumpulan data; 2) Analisa Kebutuhan; 3) Perancangan dan implemetasi; 4) Uji Coba; dan 5) Pemeliharaan.
Berdasarkan diagram alir tersebut, dapat dijelaskan bahwa pada penelitian ini terdiri dari beberapa tahapan, yaitu:

\section{Pengumpulan data}

Dalam pengumpulan data tahapan yang dilakukan dengan cara melakukan observasi (pengamatan), wawancara dan studi pustaka guna untuk mencari data-data pendukung yang berkaitan dengan penelitian untuk melakukan perancangan dan implementasi squid proxy server.

\section{Analisa kebutuhan}

Analisis kebutuhan pada tahap ini peneliti melakukan analisa terhadap kondisi jaringan. Dengan analisa tersebut peneliti mengumpulkan informasi terkait dengan penelitian yang dilakukan peneliti. Dari analisa akan diperoleh informasi mengenai permasalahan yang ada sebelum dilakukannya tahap perancangan dan pembuatan sistem.

\section{Perancangan dan implememntasi sistem}

Tahap ini peneliti mulai melakukan perancangan dan implementasi sistem yang baru sesuai dengan analisis permasalahan yang ada.

\section{Uji coba}

Setelah tahap perancangan dan implementasi system dilakukan tahap selanjutnya yaitu dengan melakukan uji coba hasil implementasi sistem yang dijadikan sebagai solusi dalam mengatasi permasalahan yang ada sebelumnya.

\section{Pemeliharaan}

Setelah dilakukan uji coba dan tidak terdapat permasalahan dari hasil implementasi maka tahap selanjutnya dengan melakukan pemeliharaan dan pemantauan sistem secara berkala agar sistem berjalan dengan baik.

Penelitian ini membutuhkan beberapa hardware (perangkat keras) dan software (perangkat lunak). Peralatan hardware maupun software dipilih disesuaikan dengan kebutuhan peneliti guna mendukung dalam pengerjaan penelitian.

Peralatan yang dibutuhkan di antaranya sebagai berikut:

1. Hardware (perangkat keras)

- Server hardware

- CPU Xeon processor

- Memory 4GB

- Disk minimum kapasitas 100 GB.

2. Software (perangkat lunak)

- OS CentOS 6.4 x86_64 (64 bits)

- Squid Proxy 


\section{HASIL DAN PEMBAHASAN}

\subsection{Analisa}

Semakin pesatnya penggunaan internet yang telah merambah di berbagai bidang, begitu juga di pabrik. Pemanfaatan internet dipabrik yang digunakan oleh para pihak karyawan untuk mendukung proses kerja dan mendapatkan informasi yang lebih cepat. Dari manfaat tersebut terkadang para pengguna layanan internet di pabrik menuntut akses internet yang dapat dilakukan secara cepat dan adanya pembatasan ke situs situs tertentu, dimana karyawan tidak boleh aksess dan juga pembatasan terhadap download file supaya kecepatan tetap terjaga dan aman secara security.. Kondisi dilapangan yang dijadikan sebagai tempat penelitian terdapat beberapa permasalah yang berkaitan dengan jaringan yang sudah ada sebelumnya. Permasalahan tersebut diantaranya keluhan dari para pengguna internet di PT UTAC koneksi akses internet yang terasa lambat untuk membuka suatu situs website secara penuh, selain itu pada jaringan yang ada belum adanya kontrol yang cukup tertata terhadap perangkat- perangkat yang terhubung dengan jaringan pabrik dan tidak adanya pembatasan pembatasan pada pengguna internet.

\subsection{Perancangan dan implementasi}

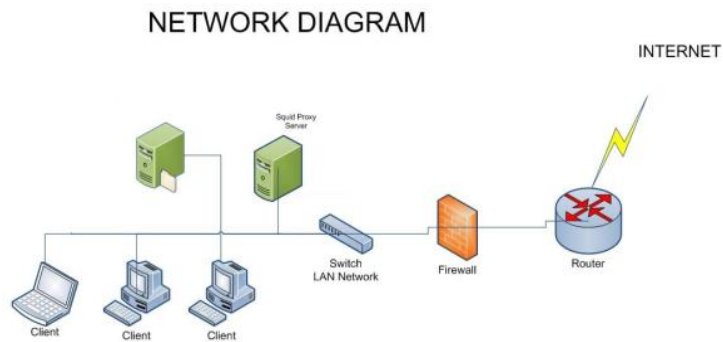

Perancangan yang diusulkan dalam penelitian ini mengunakan aplikasi Squid Proxy dan Operating System Centos berikut gambar configuration Squid Proxy

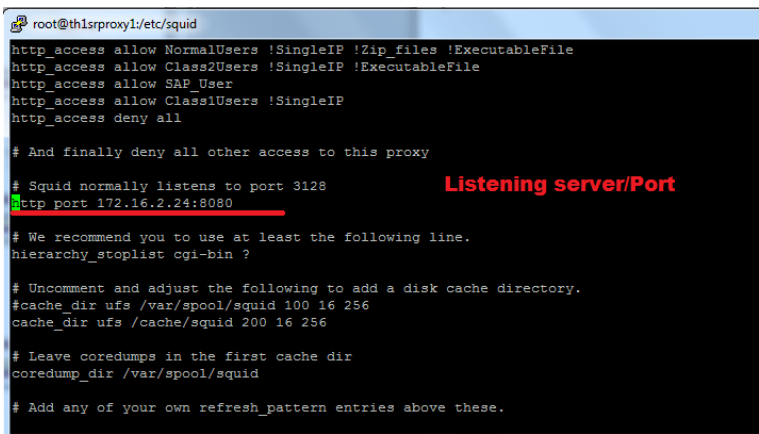

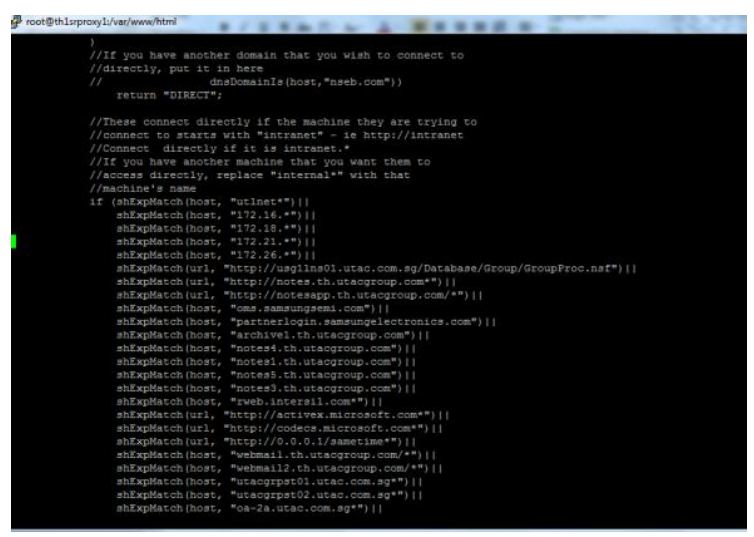
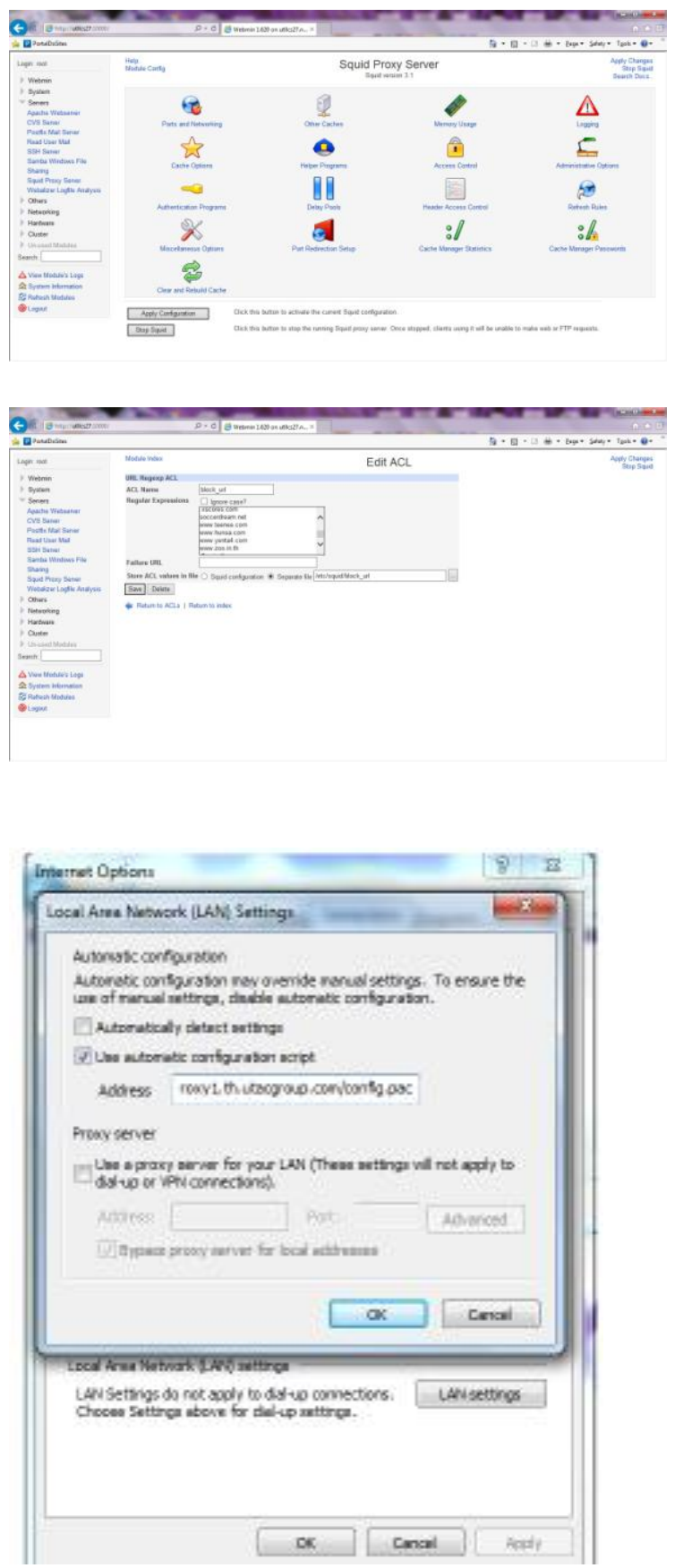
ISSN: 2503-071X

E-ISSN: 2621-511X

\section{KESIMPULAN}

Berdasarkan hasil dan pembahasan diatas dapat ditarik kesimpulan bahwa dunia teknologi informasi yang semakin berkembang secara pesat dan diikuti dengan meningkatknya pengguna dan pemakai internet. Dengan semakin meningkatnya pengguna internet maka tuntutan akan kecepatan akses internet sudah menjadi hal umum, untuk menjawab pertanyaan tersebut maka diperlukannya suatu teknologi yang dapat meningkatkan kecepatan akses internet. Untuk menjawab permasalahan tersebut penelitian kali ini peneliti mengusulkan suatu perancangan dan implementasi squid proxy server pada Centos 5.5 yang bertujuan untuk meningkatkan kecepatan akses internet sehingga permasalahan akses internet yang lambat dapat teratasi. Sistem operasi Centos Server 5.5 digunakan karena memiliki tingkat kemaanan yang lebih terjamin dan bersifat open source jika dibandingkan dengan Windows. Pemilihan squid sebagai proxy server dikarenakan squid telah terkompilasi secara langsung pada sistem operasi Centos Server 5.5.

\section{PUSTAKA}

Irsyadi FYA. 2012. Implementasi Squid Server Pada Proxy Cache Video. Jurnal Emitor. 12(1): 16 25.

Khasanah NF. 2014. Perancangan dan Simulasi Jaringan Komputer Menggunakan Graphical Network Simulator3 (GNS3). Surakarta: Universitas Muhammadiyah Surakarta.

Madcoms. 2009. Membangun Sistem Jaringan Komputer. Yogyakarta: Andi.

Pratama Y. 2010. Optimasi Squid Untuk Akses Ke Youtube: Yogyakarta.

Sanjaya R. 2005. Trik Mengelola Kuota Internet Bersama Squid. Jakarta: Elex Media Komputindo.

Siregar E. 2010. Mengelola Jaringan Lebih Efektif dan Efisien. Yogyakarta: Andi.

Sulistyo P. 2008. Membangun Infrasturktur IT Menggunakan Squid Sebagai Proxy Server (Stdui Kasus Universitas Sahid Surakarta) 